\title{
ON THE CHEMICAL NATURE OF CERTAIN GRANULES IN THE INTERSTITIAL CELLS OF THE TESTIS
}

\author{
R. H. WHITEHEAD \\ From the Anatomical Laboratory, University of Virginia
}

SIX FIGURES

In the course of a previous communication the writer $^{1}$ called attention to the existence of certain granules in the interstitial cells of the testes of various mammals. The present paper gives the results of an attempt to control the previous observations, and also to obtain some insight into the chemical nature of these bodies.

The granules were detected first in the cat's testis fixed in formalin, and I shall begin the present account by a brief description of the appearances noted in such material. In paraffin sections the granules may be demonstrated by a number of staining methods, of which Reinke's neutral gentian as employed by Bensley ${ }^{2}$ is excellent. Here the cytoplasmic framework of the cells is stained by the orange $\mathrm{G}$, while the granules take the violet dye (fig. 1), as does also the chromatin of the nucleus. The cytoplasm is extensively vacuolated owing, for the most part, to the solution of large quantitics of lipoids by the reagents employed in imbedding. The violet-colored granules are fairly spherical in contour, and vary as to size. They are sprinkled here and there in the cell-body, but are most numerous in the peripheral portion of the

${ }^{1}$ R. H. Whitehead. Studies of the interstitial cells of the testis. Histology. Anat. Rec. of Amer. Your. Anat., vol. 7, no. 4, 1908. I have remarked elsewhere that this paper is catalogued "in the German literature" under a misleading title. Dr. P. Mayer informs me that it is cited correctly in Zool. Jahresb. f. 1908. My statement was too broad, and I take the first opportunity to correct it.

2 R. R. Bensley. Studies on the panereas of the guinea pig. Amer. Jour. Anat., vol. $12,1911$. 
cell. However, they may be located in any portion of the cellbody; often some are found in the vicinity of the nucleus, occasionally in apparent contact with the nuclear membrane. It can be determined that they lie in vacuoles, though some of the smallest granules appear to be located at the nodal points of cytoplasmic threads. It would seem that the number of the granules varies with different individuals. Thus in one cat there were few cells observed that contained more than two or three granules; in this animal the number and size of the cells also seemed decidedly below the average.

A very clear picture was obtained with Wright's blood stain. The sections were stained twenty-four hours in a dilute solution (one part of dye to forty of distilled water), the excess of dye was washed out with distilled water, and the sections were then dehydrated in acetone, cleared in xylol, and mounted in neutral balsam. The granules were stained red, the chromatin took the methylene blue, and the general cytoplasm was stained blue or pinkish blue (fig. 2). Sections of this material stained with Altmann's solution of acid fuchsin gave essentially the same appearances so far as the granules were concerned; but in this case the picture was not so clear owing to the fact that both the cytoplasm and the granules were stained by the acid fuchsin; the granules, however, were a much deeper red. I would call especial attention to the fact that in none of the preparations mentioned above were any mitochondrial structures demonstrated in the seminal epithelium.

Iron haematoxylin gave a somewhat different picture (fig. 3). Here the spongioplasmic framework was well stained in many cells, so that it sometimes presented the appearance of threads of small granules (mitochondria). In such cases granules might be present in somewhat confusing number; but the distinction between the two sorts could usually be made owing to the fact that the granules were larger than the spongioplasmic structures, were more regularly spherical, and were contained in vacuoles, whose walls were furnished by trabeculae of the spongioplasm. In these preparations mitochondrial structures were seen also in the seminal epithelium, threads of bacilli-like grains in the Sertoli cells being brought out with especial distinctness. 
In material fixed in absolute alcohol the granules, in spite of the distortion of the cells, were still quite evident and apparently undiminished in number.

In the previous communication it was stated that the granules could not be stained in material fixed by solutions which contained potassium bichromate in large proportion. This statement was based on the negative results obtained with pieces of cat's testis fixed in several fluids which contained that salt in considerable amount. I am unable to say just where the error came in, but the statement was certainly erroneous. Hanes ${ }^{3}$ has demonstrated the granules in pig's testis fixed in Zenker's fluid, and I have myself repeatedly observed them in this material fixed by Zenker. I have investigated the point anew in the cat's testis as well as the pig's, and find that the granules, while present, are more or less disfigured: they are apt to lose their regularly spherical contour and appear as irregular lumps, or as spherules with darkly stained periphery and lighter center. This disfiguration, however, is possibly due to the acetic acid contained in the Zenker's fluid.

From the above we may conclude that the granules described in formalin and absolute alcohol material are proteid in nature. They may be stained with either basic (gentian violet) or acid (acid fuchsin) dyes; but when given an equal opportunity at the methylene blue and the eosin in Wright's stain take the eosin.

In the course of a recent study of the lipoids of these cells ${ }^{4}$ in the cat it was noticed that along with the globules of lipoids the interstitial cells frequently contained granules with an affinity for Sudan III which, in respect of size and position, were indistinguishable from the granules just described. The suggestion presented itself that the granules really consist of a combination of proteid and fatty material, and that in paraffin sections of material fixed in formalin or absolute alcohol the fatty constituent had been dissolved out, leaving only the proteid. It seemed highly improbable that any fatty matter would remain in sections

3 F. M. Hanes. The relation of the interstitial cells of Leydig to the production of an internal secretion of the mammalian testis. Jour. Exp. Med., March, 1911.

${ }^{4} \mathrm{R}$. H. Whitehead. A microchemical study of the fatty bodies of the interstitial cells of the testis. Anat. Rec., vol. 6, 1912. 
of material which had been subjected to this treatment, but inasmuch as Fauré-Fremiet, Mayer and Shaeffer ${ }^{5}$ have reported that some combinations of proteid and fat are precipitated by formalin, the point was tested by staining paraffin section of formalin material with Sudan. The results were always negative; even the strong solution of Sudan made by the addition of caustic soda, according to Herxheimer's method with scharlach, left the granules unstained.

Various attempts were made to verify the hypothesis that the granules consist of a combination of proteid with fatty material by staining methods intended to demonstrate the granules and the lipoid globules in different colors in the same cell, but as none of these yielded decisive results, I may omit a detailed description of them, and state the results of two which were, at least, strongly suggestive. Pieces of formalin material were treated for three days with Flemming's fluid, imbedded in paraffin, sectioned, and the sections stained with neutral gentian and mounted in xylol balsam. In such sections the lipoid globules as well as the granules were stained by the gentian, but the violet color rapidly faded out of the globules leaving the granules stained violet. Again, in sections of material fixed by Ciaccio's method and stained with Sudan and iron haematoxylin lipoid globules were stained red, while here and there among them were small granules stained by the haematoxylin. It did not seem possible, however, to identify these latter absolutely with the granules in question, because it is known that some lipoids after treatment with potassium bichromate give a lake with haematoxylin; and so these haematoxylin-stained grains may have been simply such lipoids without any proteid admixture. Thus the large amount of lipoids in the cat's testis introduced so much confusion into the picture that it did not seem possible to get decisive results from this method of investigation. Accordingly recourse was had to the pig's testis, as a previous study ${ }^{6}$ of it had shown almost entire

${ }^{5}$ Faurć-Fremiet, Mayer et Shaeffer. Sur la microchemie des corps gras. Arch. d'Anat. Microse., T. 12, 1910.

${ }^{5} \mathrm{R} . \mathrm{H}$. Whitehead. Studies of the interstitial cells of the testis. Histology. Anat. Rec. of Amer. Jour. Anat, vol. 7, no. 4, 1908. 
absence of lipoid material so far as the interstitial cells were concerned.

In the pig the general histological characters of the interstitial cells are essentially the same as in the cat; there are, however, some differences which require to be mentioned. The lipoid globules which are so abundant in the cat are virtually absent; consequently the large vacuoles left in the cytoplasm by the solution of thesc bodies are also absent, and the spongioplasmic framework is much tighter. There is, however, an abundance of small vacuoles towards the periphery of the cells. In sections of formalin material stained by ncutral gentian the appearances presented by the granules is about the same as in the cat, except that they are, perhaps, more variable as to size. In preparations stained by iron haematoxylin or by Altmann's acid fuchsin or by Benda's method (after fixation in Flemming's fluid) and in which differentiation has not been carried very far, there is often an embarrassment of granules, and the entire cell-body may appear stuffed with them. A little study shows, however, that in the vicinity of the nucleus small grains predominate, while towards the periphery of the cell larger ones become more numerous; moreover, the small granules often appear arranged in threads. If the differentiation has been well carried out, until the structure of the nucleus is well shown, the small grains give up the stain and the picture does not differ from that exhibited by the preparations stained with neutral gentian, i.e., a number of granules lying in small vacuoles and most numerous at the periphery of the cell (fig. 4). I take it that the small granules arranged in. threads are the mitochondrial struetures of the cells, and that the larger ones in vacuoles are the granules under discussion.

This material seemed ideal for applying the test of direct staining of the granules with a specific fat dye such as Sudan III, as there should be absence of the confusion encountered in the cat's testis due to the presence of many globules of lipoids. Thin frozen sections were stained for half an hour in the incubator at $37^{\circ} \mathrm{C}$. with a saturated solution of Sudan III in 70 per cent alcohol, but on examination proved practically negative. Fatty material within the seminiferous tubules was demonstrated in large amount 
but the interstitial cells contained no red-staining material. Thinking that the failure to stain might be due to the small size of the granules, recourse was had to the strong solution recommended by Herxheimer for scharlach (absolute alcohol $70 \mathrm{cc}$, 10 per cent solution of caustic soda $20 \mathrm{cc}$., distilled water $10 \mathrm{cc}$., Sudan to saturation) with the result that sections stained ten or fifteen minutes at room temperature offered a very satisfactory demonstration of the granules in red. Some of the cells presented a quite exact reproduction in red of the picture of the granules as seen in paraffin sections stained by the other methods. They were situated in small vacuoles between the trabeculae of the spongioplasm, and were most numerous at the periphery of the cells (fig. 5). It is to be noted, however, that many of the granules appeared smaller than in the other preparations; and in many of the cells this small size of the red granules was quite pronounced, as if only a localized portion of their substance had been stained by the Sudan (fig. 6). Thus there was obtained direct proof that the granules contained fatty material in addition to the proteid constituent demonstrated by the other methods.

It remained to determine whether or not these granules should be classed with the lipochromes, as fatty pigment has been found in the interstitial cells of several mammals. According to Sehrt, ${ }^{7}$ who has made an extensive study of this pigment in the human testis, it is stained by Sudan even in sections of material that has been imbedded in paraffin. In the case of the pig and the cat the granules were colorless in frozen sections, and it was not possible to stain them with Sudan in paraffin sections of formalin material. It seems certain, therefore, that the granules are not lipochrome.

From this study I conclude that the granules in the interstitial cells of the pig, and probably also of the cat, consist of a combination, either physical or loosely chemical, of proteid with fatty material. It also shows that the pig's interstitial cells, which contain no individual globules of lipoids, are no exception to the

${ }^{7}$ Sehrt. Zur Kenntniss der fetthaltigen Pigmente. Virchow's Arch., Bd. 177, 1904 . 
general rule that these cells, aside from any other function that may be ascribed to them, serve as a storehouse for fatty material.

Finally, one may ask if these observations throw any light upon the histological nature of the granules. Are they derived from the chromatin of the nucleus, i.e., are they chromidial in nature? In favor of a nuclear origin is the fact that while the majority of the granules lie in the peripheral portion of the cell, it is common to find some in the neighborhood of the nucleus; in fact, they may be found lying against the nuclear membrane. Moreover, with most staining methods the granules and the chromatin are stained by the same dye. Such observations are, of course, merely suggestive. On the other hand, when the granules and the chromatin were given an equal opportunity at an acid and a basic dye without any more differentiation than was obtained by washing with distilled water, the chromatin took the basic, while the granules preferred the acid dye (fig. 2). So that, if one assumed that the granules are derived from the nucleus, he would also have to assume that they undergo a change in chemical nature as soon as they escapefrom the nucleus. Somewhat more direct seems the evidence in favor of their derivation from the cytomicrosomes-Altmann's granules, mitochondria, or whatever name shall be given to the small granules located in the trabeculae of the spongioplasm. As we have seen, it is quite possible to stain these at the same time with the granules. Apparently all that is needed to convert them into the granules is the incorporation of fatty material and increase in size; there would thus be produced the picture of granules lying in small vacuoles of the spongioplasm.

Another question which presents itself is, are these granules mitochondria? If Benda's dictum is correct, that his staining method for mitochondria is specific and that all cytoplasmic structures which stain by this method are mitochondria, then these granules are undoubtedly mitochondria. It may be pointed out further that Faure-Fremiet, ${ }^{8}$ Regaud and others have presented evidence--evidence based for the most part upon deduc-

${ }^{8}$ Fauré-Fremiet, Mayer et Shaeffer. Sur la microchemie des corps gras. Areh. d'Anat. Microse., T. 12, 1910. 
tions from the chemical processes believed to occur during fixing and staining - to show that mitochondria chemically considered consist of a combination of proteid with fatty material, which as we have seen, is also the constitution of the granules described in this paper. On the other hand, so far as I am aware, undoubted mitochondria, such as those of the sex cells, have not been stained by a specific fat stain. However that may be, it does not seem possible that the mitochondria of the sex cells of the cat and pig can be identical with the granules in the interstitial cells; for in my paraffin sections of formalin material stained by neutral gentian or Wright's blood stain the granules of the interstitial cells were demonstrated very clearly, while in the seminal epithelium absolutely no granules were stained. So that, for the present, one may be permitted to believe with Heidenhain, ${ }^{9}$ that while Benda has probably brought to light new structures in the case of the mitochondria of sex cells, it is carrying his results too far to identify mitochondria with all cytoplasmic structures which can be stained by his method.

PIATE 1

EXPLANATION OF FIGURES

All the cells were outlined with the camera lucida. Reichert, obj. $\frac{1}{12}$.

1 Interstitial cell of eat; neutral gentian. Formalin fixation.

2 Interstitial cell of cat; Wright's blood stain. Formalin fixation.

3 Interstitial cell of cat; iron haematoxylin. Formalin fixation.

4 Interstitial cell of pig; iron haematoxylin. Formalin fixation.

5 Interstitial cell of pig; Sudan III. Frozen section.

6 Interstitial cell of pig; Sudan III. Frozen section.

${ }^{9}$ M. Heidenhain. Plasma und Zelle, 1907. 


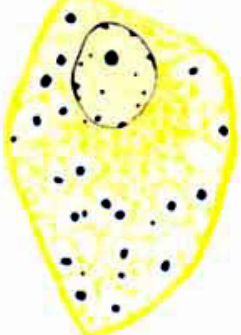

1

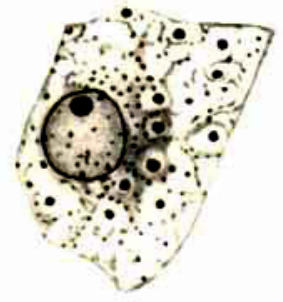

3

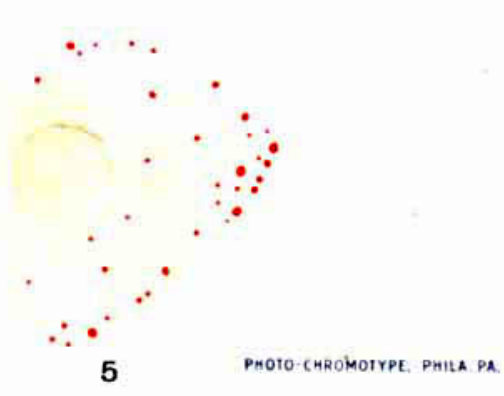

4

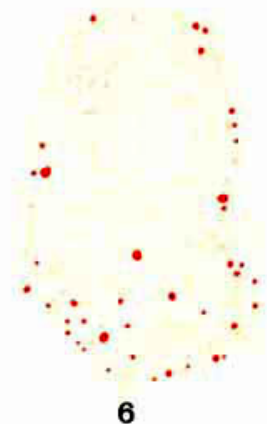

THE AMERICAN JOURNAL OF ANATOMY, VOL. 14, NO. 1 